\title{
Extra-articular synovial osteochondroma of the Hoffa's fat pad involving the patellar tendon: A case report and literature review
}

\author{
KAZUHIKO HASHIMOTO, SHUNJI NISHIMURA, KOUTARO YAMAGISHI, ICHIRO TSUKAMOTO, \\ KOICHI NAKAGAWA, SHINJI INOUE, SHIGEKI ASADA, RYOSUKE KAKINOKI and MASAO AKAGI \\ Department of Orthopedic Surgery, Kindai University Hospital, Osaka-Sayama, Osaka 589-8511, Japan
}

Received June 21, 2018; Accepted February 4, 2020

DOI: $10.3892 / \operatorname{mco} .2020 .1998$

\begin{abstract}
Synovial osteochondroma (SO) is a relatively uncommon tumor affecting the synovial joints that is characterized by the development of hyaline cartilage from the synovial membrane. The basic pathophysiology of SO is thought to be the metaplastic change of the synovium to hyaline cartilage. Large extra- or para-articular lesions in the Hoffa's fat pad are relatively uncommon. A 56-year-old woman complained of knee pain associated with a large lesion on the anterior of the right knee. She also had restricted range of motion in the knee. Examination revealed an elastic hard $8 \times 9-\mathrm{cm}$ lesion involving the patellar tendon. Computed tomography and magnetic resonance imaging demonstrated a mosaic-intensity mass lesion in the inferior side of the Hoffa's fat pad as well as the patellar tendon. The patient underwent needle biopsy. Histological analysis revealed a solitary SO. There were no atypical features suggestive of malignancy and the mass was resected marginally. The patient had no recurrence or knee functional disorder 3 years postoperatively. There are no reports of SO involving the patellar tendon with restriction of range of motion. Removal of the mass lesion for management for $\mathrm{SO}$, as in the present case, is unusual. To the best of our knowledge, this is the first case of extra-articular SO in the Hoffa's fat pad involving the patellar tendon causing a restriction of range of motion of the knee. Marginal surgical resection improved knee function.
\end{abstract}

\section{Introduction}

Synovial osteochondroma (SO) is a relatively uncommon disorder characterized by the development of hyaline cartilage tissue from the synovium (1). It typically presents as knee arthropathy, and is thought to arise from a metaplastic process

Correspondence to: Dr Kazuhiko Hashimoto, Department of Orthopedic Surgery, Kindai University Hospital, 377-2 Ohnohigashi, Osaka-Sayama, Osaka 589-8511, Japan

E-mail: hazzhiko@med.kindai.ac.jp

Key words: synovial osteochondromatosis, extra-articular, knee, patellar tendon, Hoffa's fat pad, marginal resection on the synovial membrane (2). This cartilaginous tissue may form loose bodies in the joint and become symptomatic (3). Malignant transformation to chondrosarcoma is uncommon but has been described (4). SO usually involves the joints, such as the knee, hip, ankle, elbow, wrist, and shoulder joints (5). Extra-articular lesions are relatively uncommon and mainly observed in a synovial sheath or the bursa of the foot or hand (6). Large extra-articular lesions of the Hoffa's fat pad are rare. The present study presents a case of extra-articular $\mathrm{SO}$ of the right knee in a 56-year-old woman. This is the first case of large extra-articular SO involving the patellar tendon with restriction of range of motion in the knee.

\section{Case report}

A 56-year-old woman presented at Kindai University Hospital (Osaka, Japan) with a 2-year history of knee pain associated with an enlarging mass on the anterior of the right knee. She had only a past medical history of a benign breast tumor.

Examination of the right knee joint revealed an $8 \times 9-\mathrm{cm}$ elastic hard mass lesion on the anterolateral right knee. The patient had restricted range of motion (0-130 degrees) of the knee, and deep flexion aggravated the pain. Her inflammatory markers were normal. Radiography showed enhancement of soft part shadows and calcification at the Hoffa's fat pad (data not shown). Bone scintigraphy showed abnormal accumulation in the front of the right knee in the early phase that decreased in the delay phase (Fig. 1A). Computed tomography showed an iso- to low-intensity mass involving the patellar tendon at the Hoffa's fat pad lesion with calcification (Fig. 1B and C). T1-weighted magnetic resonance imaging (MRI) showed an iso-intensity mass (Fig. 1D and E), and T2-weighted MRI showed a high-intensity mass (Fig. $1 \mathrm{~F}$ and G). We conducted needle biopsy. The histology showed synovial tissue and chondrocyte tissue fragments (data not shown). No malignancy was detected. The patient underwent marginal resection. Adhesion to the tissue surrounding the tumor mass was confirmed. The tumor mass also adhered to the patellar tendon, and we released the adhesion of the tumor mass and patellar tendon. It was easy to release the tendon from the tumor.

After the surgery, the patellar tendon was not damaged (Fig. 2A). The excised specimen showed an elastic, hard, white-yellow covering (Fig. 2B). Hematoxylin and eosin staining showed hyaline cartilage and trabecular bone 


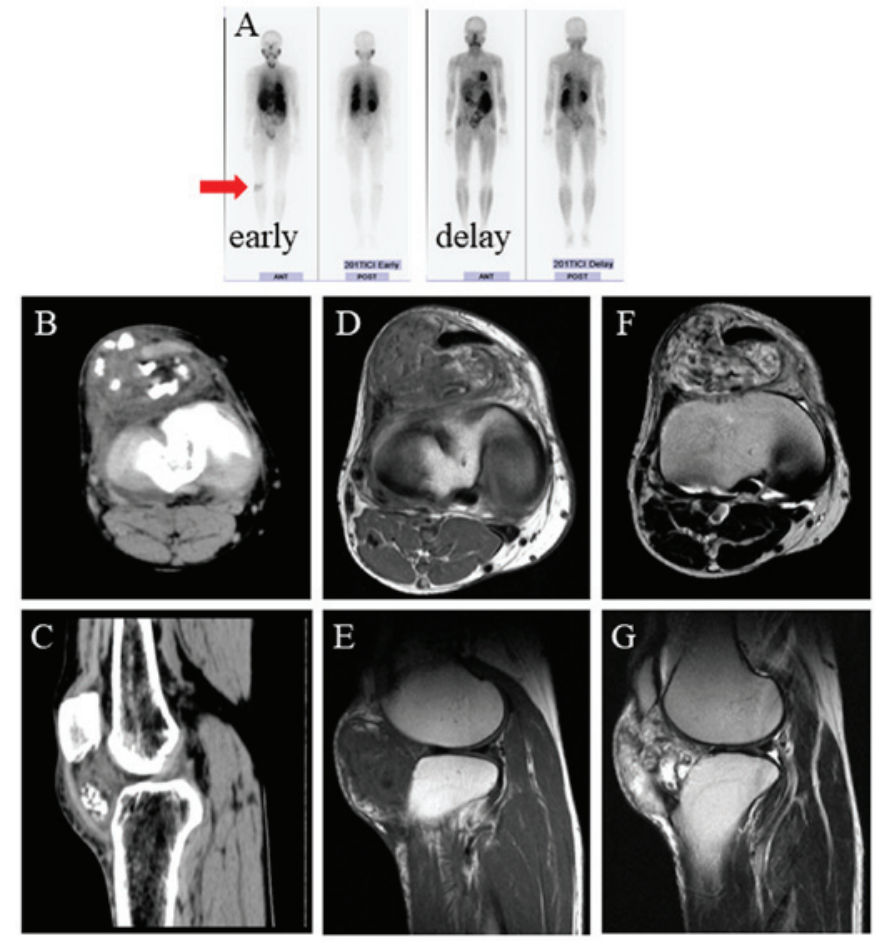

Figure 1. Bone scintigraphy. (A) Bone scintigraphy showing abnormal accumulation in the front of the right knee in the early phase that decreases in the delay phase (red arrow). Calcification is evident at the site of the Hoffa's fat pad. (B) Coronal section and (C) sagittal section of computed tomography. The tumor mass is observed in front of the knee (C and D). (D and E) T1-weighted and ( $\mathrm{F}$ and $\mathrm{G}$ ) T2-weighted magnetic resonance images (MRIs). (D and E) T1 MRI showing low-intensity mass. (F and G) T2 MRI showing a high-intensity mass.

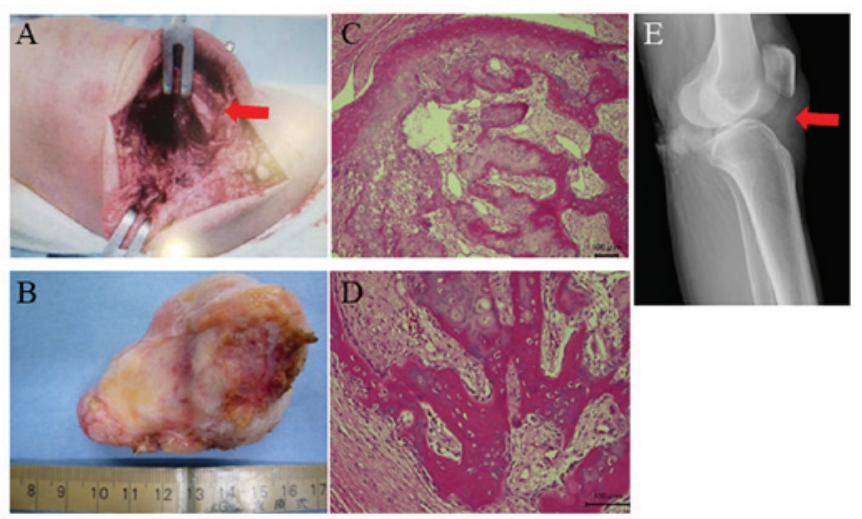

Figure 2. The surgical site findings after tumor resection. (A) There is no injury observed in the patellar tendon (red arrow). (B) The resected specimen shows a white-yellow covering. (C and D) Hematoxylin and eosin staining showing hyaline cartilage and trabecular bone formation. (C and D) Osteoblasts lined up along the trabecular bone and scattered osteoclasts. (C and D) Spindle-like cell proliferation is observed between the trabeculae. (C) Magnification, x100. (D) Magnification, x200. Scale bar, $100 \mu \mathrm{m}$. (E) Knee sagittal radiography after surgery. The patellar tendon is intact (red arrow).

formation (Fig. 2C and D). Osteoblasts lined the trabecular bone, and scattered osteoclasts were observed (Fig. 2C and D). Spindle-like cell proliferation was observed between the trabeculae (Fig. 2C and D). We diagnosed SO by the histological findings. Radiography after surgery confirmed that there was no damage to the patellar tendon (Fig. 2E). The range of motion had improved (0-145 degrees), and the knee pain during deep flexion disappeared.

\section{Discussion}

Extra-articular SO often occurs at the site of the Hoffa's fat pad (7). However, extra-articular SO involving the patellar tendon has not been previously reported. To the best of our knowledge, this is the first case of extra-articular SO involving the patellar tendon.

The etiology of para-articular osteochondroma has not been clarified (8). Metaplasia from extra-synovial mesenchymal cells can be the origin of osteochondroma (8). Repeated trauma can also cause metaplasia $(9,10)$. Moreover, SO of the Hoffa's fat pad is considered the final stage of inflammation after injury (11). The possibility of existence of occult injury history of the Hoffa's fat pad was also considered in the present case. The differential diagnosis of SO in this location includes para-articular osteochondroma, Hoffa's disease, and primary chondrosarcoma (12). Extra-articular synovial osteochondroma should be differentiated from para-articular osteochondroma of the infrapatellar fat pad (13). On histologic examination, hypercellular hyaline cartilage arising from the synovium is detected, and nuclear atypia is common. Benign synovial chondromatosis can be difficult to differentiate histologically from low-grade chondrosarcoma; some features more suggestive of malignancy include cartilaginous cells in sheets rather than clusters, myxoid changes, and the presence of necrosis (1-3). However, no definitive criteria for the diagnosis of malignancy exist. In the present case, no clear malignant findings were detected.

We observed calcification by radiography, which is common in such cases (14-16). Computed tomography or MRI more commonly lead to characterization of the lesion and can be diagnostic. Non-calcified and calcified lesions may be differentiated on MRI because non-mineralized chondromata are isointense on T1-but hyperintense on T2-weighted images (17), as observed in the present study.

With regard to the treatment of $\mathrm{SO}$, marginal resection is preferable when possible $(4,5)$. Over-wide surgical treatment should be avoided (18). Our patient underwent marginal resection and has a good prognosis without functional disorder. If restriction of knee range of motion is observed, as in the present case, resection should be performed as early as possible. Long-term follow-up is crucial because of the high rate of recurrence and risk of malignant transformation (19).

Similar tumors have been reported in recent years $(15,16)$. Both cases originated from the Hoffa's fat pad and caused knee pain. One patient demonstrated an impingement of the knee joint (15). However, unlike our case, the tumors in both cases did not show involvement of the patellar tendon. Based on these findings, the present case was more advanced than those limited to the Hoffa's fat pad. Therefore, the present case is unique in that it demonstrates that advanced cases with patellar tendon involvement may be cured by marginal resection.

\section{Acknowledgements}

We thank Editage for the English editing. 


\section{Funding}

Not applicable.

\section{Availability of data and materials}

All data generated or analyzed during this study are included in this published article.

\section{Authors' contributions}

SN, SI, KN, SA, IT, KY, RK, KH and MA analyzed and interpreted the patient data. All authors read and approved the final manuscript.

\section{Ethics approval and consent to participate}

The procedures followed were in accordance with the Ethical standards of the responsible committee on human experimentation (institutional and national) and with the Helsinki Declaration of 1975, as revised in 2013. The patients also provided written informed consent for this retrospective study.

\section{Patient consent for publication}

We obtained written informed consent for publication from the patient.

\section{Competing interests}

The authors declare that they have no competing interests.

\section{References}

1. Trevino M, Laks S, Kafchinski L, Sundarakumar DK and Smith CM: Intermetatarsal bursa primary synovial chondromatosis: Case report and review of the literature. Skeletal Radiol 46: 1769-1773, 2017.

2. Temponi EF, Mortati RB, Mortati GMH, Mortati LB, Sonnery-Cottet B and de Carvalho Júnior LH: Synovial chondromatosis of the knee in a 2-year-old Child: A case report and review of the literature. JBJS Case Connect 6: e71, 2016.

3. Raval P, Vijayan A and Jariwala A: Arthroscopic retrieval of over 100 loose bodies in shoulder synovial chondromatosis: A case report and review of literature. Orthop Surg 8: 511-515, 2016.
4. Ng VY, Louie P, Punt S and Conrad EU: Malignant transformation of synovial chondromatosis: A systematic review. Open Orthop J 11: 517-524, 2017.

5. Lohmann CH, Köster G, Klinger HM and Kunze E: Giant synovial osteochondromatosis of the acromio-clavicular joint in a child. A case report and review of the literature. J Pediatr Orthop B 14: 126-128, 2005.

6. Doral MN, Uzumcugil A, Bozkurt M, Atay OA, Cil A, Leblebicioglu G and Tetik O: Arthroscopic treatment of synovial chondromatosis of the ankle. J Foot Ankle Surg 46: 192-195, 2007.

7. O'Connell L, Memon AR, Foran P, Leen E and Kenny PJ: Synovial chondroma in Hoffa's fat pad: Case report and literature review of a rare disorder. Int J Surg Case Rep 32: 80-82, 2017.

8. Li C, Arger PH and Dalinka MK: Soft tissue osteochondroma. A report of three cases. Skeletal Radiol 18: 435-437, 1989.

9. Kautz FG: Capsular osteoma of the knee joint. Report of four cases. Radiology 45: 162-167, 1945.

10. Krebs VE and Parker RD: Arthroscopic resection of an extrasynovial ossifying chondroma of the infrapatellar fat pad: End-stage Hoffa's disease? Arthroscopy 10: 301-304, 1994.

11. Turhan E, Doral MN, Atay AO and Demirel M: A giant extrasynovial osteochondroma in the infrapatellar fat pad: End stage Hoffa's disease. Arch Orthop Trauma Surg 128: 515-519, 2008.

12. Ogura K, Goto T, Nemoto T and Imanishi J: Para-articular osteochondroma of the infrapatellar fat pad. J Knee Surg 24: 209-213, 2011.

13. Sakai H, Tamai K, Iwamoto A and Saotome K: Para-articular chondroma and osteochondroma of the infrapatellar fat pad: A report of three cases. Int Orthop 23: 114-117, 1999.

14. Osti L, Papalia R, Del Buono A, Denaro V and Maffulli N: Recurrence of synovial chondromatosis of the Hoffa's body. Knee Surg Sports Traumatol Arthrosc 17: 1421-1424, 2009.

15. Maljanovič M, Ristič V, Rasovič P, Matijevič R and Milankov V: Solitary synovial chondromatosis as a cause of Hoffa's fat pad impingement. Med Pregl 68: 49-52, 2015.

16. Lee DH and Jeong TW: Uncommon primary synovial chondromatosis involving only the infrapatellar fat pad in an elderly patient. Knee Surg Relat Res 28: 79-82, 2016.

17. Sheldon PJ, Forreste DM and Learch TJ: Imaging of intraarticular masses. Radiographics 25: 105-119, 2005.

18. Maheshwari AV, Muro-Cacho CA and Pitcher JD Jr: Extraskeletal para-articular osteochondroma of the posterior knee. J Knee Surg 22: 30-33, 2009.

19. Bashaireh KM: Patellar subluxation with early-phase synovial chondromatosis of the knee. Orthopedics 39: e176-e179, 2016.

This work is licensed under a Creative Commons Attribution-NonCommercial-NoDerivatives 4.0 International (CC BY-NC-ND 4.0) License. 